\title{
A STUDY ON TINEA CAPITIS IN THE PRE SCHOOL AND SCHOOL GOING CHILDREN
}

\author{
by Neerja Puri, Asha Puri
}

\author{
comment: \\ Dr. Rajesh Jeewon Ph.D. \\ Department of Health Sciences, Faculty of Science, Reduit, \\ University of Mauritius, Mauritius \\ E-mail:r.jeewon@uom.ac.mu
}

\author{
Source of Support: \\ Nil \\ Competing Interests: \\ None
}

This study by Puri N \& Puri A provides an overview of the prevalence of Tinea capitis among school children in some parts of India.

Tinea capitis (TC) (scalp ringworm) poses a significant health problem in many underdeveloped and developing countries. It is the most common dermatophyte infection in childhood and primarily caused by fungal dermoatophytes in the Trichophyton and Microsporum genus. The epidemiology of TC varies within different geographical areas throughout the world and a number of studies have clearly demonstrated that there is a significant increase in its incidence and a change in the pattern of infectious agents in different countries and a similar trend can be observed in India as well.

Data provided by the authors are interesting but the results could have been expanded and compared with other recent studies. Given the sporadic nature of the causal agents, which vary within different geographical areas, a proper comparison is warranted so that early diagnosis and adequate treatment can be done promptly. While the authors here found that Black dot type and T. violaceum were more prevalent; more males were infected than females as the latter frequently apply vegetable oil over scalp, such is not the case in other parts of the world, even in different states in India.

For instance, a recent study assessing the prevalence of Tinea capitis among urban school children in Kolkata, (India), Bindu et al (2012) found that the prevalence rate was significantly high among boys but there was no significant difference in prevalence of infection among coconut oil users and castor oil users. In addition, they also reported that the commonest clinical type of infection found was dull grey patches as compared to Black dot type observed by Puri N \& Puri A. However, it should be mentioned that the use of oils to reduce TC is quite well known as these oils contain different percentages of various saturated and unsaturated fatty acids which largely determine their toxicity against dermatophytes (Garg \& Muller, 1992).

In another study, Ayaya et al (2001) reported there were more males school children in Africa that were infected than females (ratio of 2:1) and this corroborates with what Puri $\mathrm{N}$ and Puri A found. In addition, most of the cases reported were of endothrix and similar findings are reported by Puri $\mathrm{N}$ and Puri A. The major difference between the two studies was in the infectious agent. While Ayaya et al (2001) commonly isolated T. tonsurans, Puri N and Puri A reported T. violaceum as more prevalent. Other studies that have reported violaceum as more prevalent include those of Chepchirchir et al (2009) in Kenya. The latter also found that the grey patch form was the dominant clinical manifestation contrary to Puri $\mathrm{N}$ and Puri A. In Kuwait, the non-inflammatory "grey patch" variety has also been reported to be the most common clinical type, followed by black-dot variant and that $T$. violaceum was the most common fungus responsible for the black-dot variety (Nawaf et al 2003).

It is noteworthy to mention that not only Trichophyton might be more prevalent than Microsporum and this may vary from regions to regions. Mycological data on TC collected in urban and rural areas of the Dominican Republic by Arenas et al (2010) reported a higher occurrence of Microsporum audouinii than Trichophyton tonsurans, Microsporum canis and Trichophyton violaceum from children in urban areas, whereas T. tonsurans and T. mentagrophytes were isolated from those in rural areas and in addition $T$. violaceum was rarely reported (in contrast to Puri N and Puri A). Similarly, Ross et al (1993) found that the dermatophytes responsible for TC in Puerto Rico were mainly M. canis.

\section{REFERENCES}

1. Ayaya SO, Kamar KK, Kakai R: Aetiology of tinea capitis in school children. East Afr Med J. 2001;78:531-5.

2. Ross S, Rubianes EI, Lugo-Somolinos A, Vázquez-Botet M, Sánchez JL: Epidemiological study of tinea capitis in Puerto Rico. P R Health Sci J. 1993;12:287-9.

3. Nawaf AM, Joshi A, Zaki A, Nour-Eldin O, Al-Sheltawy M, El-Adawy I, et al: Tinea capitis among children and adolescents in the Farwaniya region of Kuwait. J Dermatol. 2003;30:904-9.

4. Chepchirchir A, Bii C, Ndinya-Achola J: Dermatophyte Infections In Primary School Children In Kibera Slums Of Nairobi. East African Med J 2009;86:59-68.

5. Arenas R, Torres E, Amaya M, Rivera ER, Espinal A, Polanco M, et al: Emergence of Microsporum audouinii and Trichophyton tonsurans as Causative Organisms of Tinea Capitis in the Dominican Republic. Actas Dermosifiliogr. 2010;101:330-5.

6. Kundu D, Mandal L, Sen G: Prevalence of Tinea capitis in school going children in Kolkata, West Bengal . J Nat Sci Biol Med. 2012;3:152-5.

7. Garg AP, Muller J: Inhibition of growth of dermatophytes by Indian hair oils. Mycoses, 1992;35:363-9. 